\title{
The Physico-Chemical Influences of Yellow Mustard Paste - Comparison with the Powder in Mayonnaise
}

\section{Adeli Milani ${ }^{*}$, M. Mizani ${ }^{2}$, M. Ghavami ${ }^{3}$ and P. Eshratabadi ${ }^{4}$}

${ }^{1}$ Academic Member of Department of Food Science and Technology, Islamic Azad University, Hidaj Branch, zanjan, Iran

${ }^{2}$ Associate Professor of College of Food Science and Technology, Islamic Azad University, Science and Research Branch, Tehran, Iran

${ }^{3}$ Professor of College of Food Science and Technology, Islamic Azad University, Science and Research Branch, Tehran, Iran

${ }^{4}$ Assistant Professor of Institute of Standard and Industrial Research of Iran, Iran

\begin{abstract}
The aim of this study was to investigate the influences of different concentrations of yellow powder and paste mustard on viscosity, stability, rancidity and organoleptic properties of mayonnaise sauce. The concentrations of mustard in $0 \%, 0.01 \%, 0.02 \%, 0.03 \%, 0.04 \%, 0.05 \%$ and $1 \%$, were used in mayonnaise formulation and the results turned out to signify an increase in viscosity, improvement in the other chemical properties with the increasing of the amounts of powder mustard. The sensory properties evaluation demonstrated undesired changes in color and flavor of mayonnaise $(p \leq 0.05)$. Thus, in the next step a thermal treatment applied on powder mustard during which myrosine enzyme and the effective factor in pungent flavor of mustard were deactivated. The produced material, called paste mustard, and with the concentrations of $0 \%, 0.75 \%, 1 \%, 1.25 \%$ and $1.5 \%$ were used in the production of mayonnaise samples in fully the same circumstances and the above tests all repeated. The results of physiochemical tests and evaluation of sensory properties in comparison of what was observed showed a remarkable increase in viscosity, stability improvement and reduction of rancidity in samples containing paste mustard. However, the undesired changes in color and flavor of the sauce were removed to some extent and the sensory properties of the samples ameliorated $(p \leq 05)$. The research results concluded that mayonnaise sample containing $1 \%$ paste mustard without any synthetic preserver, due to high viscosity, appropriate suspension stability, rancidity reduction rate and concerning the desirability of its organoleptic features recognized as the most appropriate sample.
\end{abstract}

Keywords: Mayonnaise sauce; Yellow mustard paste and powder; Physiochemical properties

\section{Introduction}

Mustard is a nutritious food containing primarily of protein and fat. The antimicrobial, emulsifier, antioxidant, cancer chemo protective of mustard have been proved in different researches [1]. Yellow mustard is the name of a plant from the cruciferae family and sinapis Alba genus. The consumption amount of mustard, in recent formulation of food products, particularly in, sauces and meat products has been increased not only as a flavor but for the improvement of physiochemical properties and food products durability. Thus knowing the different functional properties of mustard in food industry seems necessary. Yellow mustard has more emulsifying activity index by containing two of the major polypeptides ( 50 to $55 \mathrm{kDa}$ ) than other mustards and its presence in nutritional emulsions improve the stability of the product [2]. Yellow mustard mucilage with the increasing continuous phase viscosity and thus through the impact and reduction of separation of particles in the dispersed phase in the oil in water emulsion acts as a stabilizer. The effect of hydrocolloid especially Mucilage of yellow mustard seeds compared with other hydrocolloids such as locust bean, guar, xanthan are an index of emulsion properties of this combination $[3,4]$.

The physicochemical properties of heated yellow mustard through radio frequency method (RF) in pork liver paste and mayonnaise was demonstrated that due to RF treatment the mustard seed became free of pungent flavor without significant changes in amino acids and fatty acid content of mustard while the stability of emulsion containing RF treated mustard were better than the control sample. Finally, the researchers proposed the usage of $1.5 \%$ mustard powder processed with the above method for producing meat products with more desirable emulsion stability [5]. The effects of yellow mustard Mucilage in rice and wheat starch was demonstrated that the Mucilage of yellow mustard was the reason for increasing the viscosity, adhesiveness, chewiness and springiness of rice and wheat starch without any effect on their gelatinization temperature [6]. The pungency of mustard seed arise from production of 4-hydroxybenzyl isothiocyanate from 4-hydroxybenzyl glucosinolate (Sinalbin) by the action of myrosine enzyme. Myrosinase is located in Aleurone layer and in the vacuoles surrounded by membrane called Tonoplast $[1,7,8]$. The mustard seed contains natural antioxidants. Antioxidant activity of yellow mustard with compounds such as tocopherole, compounds of hydroxybenzoic family, Trihydroxy phenolic compounds like flavones, flavonols (kaemferol, isorahmnetin) and ascorbic acid help to protect the oil from rancidity in emulsion with high content of oil [9-14]. The purpose of this study is to investigate the influences of different concentrations of yellow mustard paste and powder on viscosity, stability, rancidity and sensory properties of mayonnaise compared with different concentrations of yellow mustard powder and to eliminate adverse changes resulting from greater amounts of mustard powder in flavor and color samples and ultimately to improve the sensory and physicochemical properties of mayonnaise.

${ }^{*}$ Corresponding author: M. Adeli milani, Academic Member of Department of Food Science \& Technology, Islamic Azad University, Hidaj Branch, zanjan, Iran, Tel: +98 09125627434; Fax: +98 026 34601592; E-mail: m.milani@hidajiau.ac.ir

Received December 11, 2012; Accepted December 28, 2012; Published January 05,2013

Citation: Milani MA, Mizani M, Ghavami M, Eshratabadi P (2013) The PhysicoChemical Influences of Yellow Mustard Paste - Comparison with the Powder in Mayonnaise. J Food Process Technol 4: 210. doi:10.4172/2157-7110.1000210

Copyright: $\odot 2013$ Milani MA, et al. This is an open-access article distributed under the terms of the Creative Commons Attribution License, which permits unrestricted use, distribution, and reproduction in any medium, provided the original author and source are credited. 


\section{Materials and Methods}

\section{Materials}

Yellow mustard powder was provided from G.S.DUN Company in Canada, and other materials, including vinegar, eggs, soybean oil, sugar, guar gum, xanthan, salt, water and citric acid, was in accordance with national standard of Iran. By selecting of yellow mustard, as a natural additive, in order to evaluate its effect on viscosity, rancidity, stability, and to achieve an optimal formulation and finally producing a product with good sensory properties, in the first stage, different concentrations of yellow mustard powder utilize to reduce rancidity, increase viscosity, improve the stability and sensory properties of mayonnaise. In second stage, by using more concentrations of yellow mustard paste to increase and improve the functional properties of color and flavor of the mayonnaise, some samples were provided (Table 1 and 2).

\section{Sample preparation}

The process of mayonnaise production and the way of combining the materials is that of James Peterson and Mary et al in 1998 [15]. Weight of each batch produced according to different types of mayonnaise based on the functional formulation and according to the national standards of Iran was set $3 \mathrm{~kg}[16,17]$ (Table 3).

\section{Methods}

Experiments: In order to determine the physicochemical properties of yellow mustard, the concentrations $0 \%, 0.1 \%, 0.2 \%, 0.3 \%$, $0.4 \%$ and $0.5 \%$ of yellow mustard powder in the samples of $\left(\mathrm{F}_{11}-\mathrm{F}_{15}\right)$ and concentrations of $0.75 \%, 1 \%, 1.25 \%$, and $1.5 \%$ of yellow mustard paste in samples $\left(M_{1}-M_{4}\right)$ were used in the formulation applied for mayonnaise. The produced samples were measured in terms of rancidity, viscosity, stability, and color value.

Determination of peroxide value: Peroxide value was measured According to [18] and the method presented by Zlender in 2002. In order to evaluate the effect of different concentrations of mustard on

\begin{tabular}{|l|l|l|l|l|l|l|}
\hline Mustard (\%) & $0.0 \%$ & $0.1 \%$ & $0.2 \%$ & $0.3 \%$ & $0.4 \%$ & $0.5 \%$ \\
\hline Sample name & CS & F11 & F12 & F13 & F14 & F15 \\
\hline
\end{tabular}

Table 1: The treated mayonnaise samples with mustard powder and without benzoate sodium and Potassium sorbate.

\begin{tabular}{|l|l|l|l|l|l|}
\hline Mustard (\%) & $0.0 \%$ & $0.75 \%$ & $0.1 \%$ & $0.125 \%$ & $0.15 \%$ \\
\hline Sample name & CS & M1 & M2 & M3 & M4 \\
\hline
\end{tabular}

Table 2: The treated mayonnaise samples with mustard paste and without benzoate sodium and Potassium sorbate.

\begin{tabular}{|l|l|}
\hline Ingredients & Weight (\%) \\
\hline Soya bean oil & 63.26 \\
\hline Egg & 9 \\
\hline Sugar & 3.85 \\
\hline Guar gum & 0.1 \\
\hline Xanthan gum & 0.4 \\
\hline Salt & 1.3 \\
\hline Water & 17.37 \\
\hline Vinegar & 5.2 \\
\hline Citric Acid & 0.14 \\
\hline Potassium sorbate & 0.00 \\
\hline Sodium benzoate & 0.00 \\
\hline Mustard & $0.0-1.50$ \\
\hline
\end{tabular}

Table 3: Percentage recipes of the mayonnaise without potassium sorbate benzoate (Wt. \%). rancidity, oil extraction in treated samples and measuring peroxide value was performed in intervals of 24 hours, 1 month, 2 months and 3 months after production. The mean of results was calculated of three replicates per treatment.

Emulsion stability measurement: The Emulsion stability of mayonnaise was measured by a method provided by U.S. Department of Agriculture (USDA). Full unopened treated samples Placed in an incubator at $38^{\circ} \mathrm{C}\left(100^{\circ} \mathrm{F}\right)$ for 56 hours and emulsion stability were studied after 56 hours based on these parameters.

(status1): complete stability of emulsion without surface film of oil

(status2): accumulating one or a few drops of oil on the surface of mayonnaise.

(status3): separation of the oil and accumulating of about $1 \mathrm{~cm}$ thickness of oil on the surface of mayonnaise.

To investigate the stability of suspension in long period of time, treated samples were placed inside a carton at $20 \pm 5^{\circ} \mathrm{C}$ and evaluated after 1, 2, and 3 months after production [19].

Viscosity measurement: The viscosity of the mayonnaise was measured with a mechanical viscometer (Brookfield Model DV-II + ).Viscosity measurement taken at $10 \mathrm{rpm}$ using a T-C spindle from the helipath spindle set under fully equal laboratory conditions with controlled temperature at $22 \pm 1^{\circ} \mathrm{C}$.

Measurements were taken after one week period and all values recorded in centipoises $(\mathrm{Cp})$.

Data analysis: The Data of peroxide value, viscosity with triplicate measurements were analyzed by using the statistical analysis system software program, version 8.1 (SAS) and Duncan's multiple range test with examination for significant different $(\mathrm{p}<0.5)$ at storage interval for individual treatment. Stability data were analysis by non-parametric statistical (kruscal-wallis) test and sensory data were analyzed by ANOVA and t-test for separation of mean differences.

\section{Results and Discussion}

\section{Stability of treated samples containing yellow mustard paste and powder}

Table 4 shows the emulsion stability of mayonnaise by using different concentrations of yellow mustard powder $(0.0 \%, 0.1 \%, 0.2 \%$, $0.3 \%, 0.4 \%$, and $0.5 \%)$ in samples $\left(\mathrm{F}_{11}-\mathrm{F}_{15}\right)$ and yellow mustard paste $(0.0 \%, 0.75 \%, 0.1 \%, 1.25 \%$ and $1.5 \%)$ in samples $\left(\mathrm{M}_{1}-\mathrm{M}_{4}\right)$ and control sample (CS).

The results of statistical method Kruscal - Wallis test with 5\% probability level data indicate a direct relationship between increased concentration in the samples of mustard mayonnaise and the amount of suspension emulsion stability of mayonnaise samples.

According to the results of table 4, the suspension stability of all produced samples at $38^{\circ} \mathrm{C}$ for 56 hours was in accordance with stability test standard of mayonnaise in United States Institute of Agriculture (USDA) and after the lapse of one month from the production date, samples containing concentration of $0.1 \%, 0.2 \%$ and $0.3 \%$ and the control with and other produced mayonnaise samples were desirable and had no surface oil corrosion. The suspension stability results of mayonnaise samples, also, after the lapse of one month after production date at ambient temperature indicated that the presence of mustard was effective in the incensement of stability. Emulsion of mayonnaise as in control samples of CS and sample $\mathrm{F}_{11}$, two cases of (condition 2) 
and in samples $\mathrm{F}_{12}, \mathrm{~F}_{13}$ one case was observed and no case was observed with increasing Mustard in samples $\mathrm{F}_{14}, \mathrm{~F}_{15}$ and samples $\left(\mathrm{M}_{1}-\mathrm{M}_{4}\right)$. The emulsion Stability results of treated samples after three months from production and at ambient temperature also indicated the impact of mustard in increasing emulsion stability of mayonnaise in a way that in the samples CS the complete failure of emulsion in every three replicates and in the samples of $\mathrm{F}_{11}$ and $\mathrm{F}_{12}$ (respectively, containing 0.1 and $0.2 \%$ powder mustard), 2 cases of complete failure of emulsion and in samples $\mathrm{F}_{15}, \mathrm{~F}_{14}, \mathrm{~F}_{13}$ (respectively containing $0.3,0.4$ and $0.5 \%$ powder mustard) one case of complete failure of emulsion was observed. With the increase of mustard in samples $\mathrm{M}_{4}$ and $\mathrm{M}_{3}$ (respectively containing 1 and $1.5 \%$ paste mustard) no full failure of emulsification observed. And finally, the instability mean rating of emulsion with the increase of paste mustard, dramatically dropped to $76.70 \%$ in $\mathrm{M}_{4}$ mayonnaise samples.

\section{Rancidity evaluation of treated samples}

Table 5 shows the rancidity evaluation of mayonnaise by using different concentrations of yellow mustard powder $(0.0 \%, 0.1 \%, 0.2 \%$, $0.3 \%, 0.4 \%$, and $0.5 \%)$ in samples $\left(\mathrm{F}_{11}-\mathrm{F}_{15}\right)$ and yellow mustard paste $(0.0 \%, 0.75 \%, 0.1 \%, 1.25 \%$ and $1.5 \%)$ in samples $\left(\mathrm{M}_{1}-\mathrm{M}_{4}\right)$ and control sample (CS).

Statistical analysis by ANOVA GLM through SAS software indicates statistically significant between the mean of peroxide values in treated samples. According to Duncan test, the mean of peroxide values in treated samples indicate statistically significant between control sample (CS) and treated samples. The statistically Comparison of the cumulative mean of the results of yellow mustard powder samples $\left(\mathrm{F}_{11}-\mathrm{F}_{15}\right)$ With yellow mustard paste samples $\left(\mathrm{M}_{1}-\mathrm{M}_{4}\right)$ by twoway ANOVA method with repeated values (RPM) Indicates significant difference with a $99 \%$ level of confidence.

Table 5 showed that the peroxide value of samples $\left(\mathrm{F}_{11}-\mathrm{F}_{15}\right)$ at the intervals of three months decreased of values $5.65 \mathrm{meq} / \mathrm{g}$ to 5.03 , but decreased with the increase of paste mustard from concentrations of $0.75 \%$ and $1 \%$ respectively to $5.46 \mathrm{meq} / \mathrm{g} 5.28 \mathrm{meq} / \mathrm{g}$ due to dissolution and destruction of some compounds functioning as antioxidant such as anthocyanin and flavonone in yellow mustard and due to applying heating treatment to produce mustard paste. So that the value of peroxide with the increase of amounts of mustard paste in high values (1.5\%), decreased to $5.2 \mathrm{meq} / \mathrm{g}$. Thus rancidity reduction was quite evident again. Therefore, according to the results obtained and during investigations, it was appeared that yellow mustard powder and paste with compounds such as tocopherole, compounds of hydroxybenzoic family, Trihydroxy phenolic compounds like flavones, flavonols (kaemferol, isorahmnetin), Anthocyanin and ascorbic acid acts as antioxidant and as a result prevents the oil oxidation and product rancidity in products with high oil such as mayonnaise [8-12].

\section{Viscosity of treated samples containing yellow mustard paste and powder}

Table 6 shows the effect of different concentrations of yellow mustard powder $(0.1 \%, 0.2 \%, 0.3 \%, 0.4 \%$ and $0.5 \%)$ in samples ( $\left.\mathrm{F}_{11}-\mathrm{F}_{15}\right)$ and yellow mustard paste $(0.75 \%, 1 \%, 1.25 \%$ and $1.5 \%)$ in samples $\left(\mathrm{M}_{1}-\mathrm{M}_{4}\right)$ and control sample (CS) after one month.

Statistical analysis by ANOVA GLM through SAS software

\begin{tabular}{|c|c|c|c|c|c|c|c|c|c|c|c|c|c|}
\hline \multirow{3}{*}{$\begin{array}{l}\text { Sample name } \\
\text { CS }\end{array}$} & \multicolumn{12}{|c|}{ Time(h) } & \multirow{3}{*}{$\begin{array}{l}\text { *statistical mean rank } \\
51.50 \pm 0.00\end{array}$} \\
\hline & \multicolumn{3}{|l|}{56} & \multicolumn{3}{|c|}{1800} & \multicolumn{3}{|c|}{3600} & \multicolumn{3}{|c|}{5400} & \\
\hline & 1 & 1 & 1 & 2 & 2 & 1 & 2 & 3 & 2 & 3 & 3 & 3 & \\
\hline F11 & 1 & 1 & 1 & 2 & 1 & 1 & 3 & 2 & 3 & 3 & 2 & 3 & $40.16 \pm 11.33$ \\
\hline F12 & 1 & 1 & 1 & 1 & 2 & 1 & 2 & 3 & 2 & 3 & 3 & 2 & $40.16 \pm 11.33$ \\
\hline F13 & 1 & 1 & 1 & 1 & 1 & 1 & 3 & 2 & 2 & 2 & 3 & 2 & $28.83 \pm 11.33$ \\
\hline F14 & 1 & 1 & 1 & 1 & 1 & 1 & 2 & 2 & 2 & 2 & 2 & 3 & $28.83 \pm 11.33$ \\
\hline F15 & 1 & 1 & 1 & 1 & 1 & 1 & 3 & 2 & 1 & 2 & 2 & 3 & $28.83 \pm 11.33$ \\
\hline M1 & 1 & 1 & 1 & 1 & 1 & 1 & 3 & 2 & 1 & 3 & 2 & 2 & $28.83 \pm 11.33$ \\
\hline M2 & 1 & 1 & 1 & 1 & 1 & 1 & 2 & 2 & 1 & 2 & 3 & 2 & $28.83 \pm 11.33$ \\
\hline M3 & 1 & 1 & 1 & 1 & 1 & 1 & 1 & 2 & 1 & 2 & 2 & 2 & $17.50 \pm 0.00$ \\
\hline M4 & 1 & 1 & 1 & 1 & 1 & 1 & 1 & 2 & 1 & 2 & 2 & 1 & $12.00 \pm 5.50$ \\
\hline
\end{tabular}

a(status1): complete stability of emulsion without surface film of oil, (status2): accumulating one or a few drops of oil on the surface of mayonnaise, (status3): separation of the oil and accumulating of about $1 \mathrm{~cm}$ thickness of oil on the surface of mayonnaise. ${ }^{*}$ statistically significant $(p \leq 0.05)$. The Highest rank: The most unstable emulsion.

Table 4: Stability test results on treated samples and control (CS). ${ }^{\mathrm{a}}$

\begin{tabular}{|c|c|c|c|c|}
\hline \multirow{2}{*}{ Sample name } & \multicolumn{4}{|c|}{ Time (h) } \\
\hline & 24 * & $1800^{*}$ & $3600^{*}$ & 5400 * \\
\hline CS & $1.56 \pm 0.02$ & $3.54 \pm 0.02$ & $4.59 \pm 0.01$ & $5.85 \pm 0.01$ \\
\hline F11 & $1.44 \pm 0.02$ & $3.48 \pm 0.01$ & $4.46 \pm 0.02$ & $5.65 \pm 0.01$ \\
\hline F12 & $1.25 \pm 0.02$ & $3.35 \pm 0.01$ & $4.39 \pm 0.01$ & $5.43 \pm 0.02$ \\
\hline F13 & $1.11 \pm 0.01$ & $3.28 \pm 0.00$ & $4.24 \pm 0.00$ & $5.28 \pm 0.02$ \\
\hline F14 & $1.07 \pm 0.01$ & $5.16 \pm 0.00$ & $4.13 \pm 0.02$ & $5.15 \pm 0.00$ \\
\hline F15 & $1.01 \pm 0.01$ & $3.11 \pm 0.02$ & $4.02 \pm 0.01$ & $5.03 \pm 0.01$ \\
\hline M1 & $1.07 \pm 0.01$ & $3.24 \pm 0.02$ & $4.32 \pm 0.02$ & $5.46 \pm 0.02$ \\
\hline M2 & $0.96 \pm 0.01$ & $3.18 \pm 0.03$ & $4.11 \pm 0.01$ & $5.28 \pm 0.03$ \\
\hline M3 & $0.90 \pm 0.01$ & $3.11 \pm 0.03$ & $4.00 \pm 0.01$ & $5.17 \pm 0.03$ \\
\hline M4 & $0.83 \pm 0.01$ & $3.06 \pm 0.02$ & $4.59 \pm 0.01$ & $5.02 \pm 0.01$ \\
\hline
\end{tabular}

aMean value of tree measurements. Mean of the data which in each column bear a common letter do not have any statistical difference according to Duncan test at the leve of $5 \%$ probability, ${ }^{*}$ Statistically significant $(p \leq 0.05)$.

Table 5: Peroxide value $(\mathrm{meq} / \mathrm{g})$ on treated samples and control (CS). ${ }^{\mathrm{a}}$ 
Citation: Milani MA, Mizani M, Ghavami M, Eshratabadi P (2013) The Physico-Chemical Influences of Yellow Mustard Paste - Comparison with the Powder in Mayonnaise. J Food Process Technol 4: 210. doi:10.4172/2157-7110.1000210

Page 4 of 6

indicates statistical significant differences between the mean of viscosity measurement in treated samples. According to Duncan test the mean of viscosity value in treated samples indicates statistically significant in all of the production samples.

During the studies based on figure 1, control sample without mustard (CS) has the lowest viscosity value $(3707 \mathrm{cP})$ and with increasing concentrations of yellow mustard powder from $0.1 \%$ to $0.5 \%$, the viscosity value raised from $3759 \mathrm{cP}$ to $3898 \mathrm{cP}$. The results obtained a direct relationship between increasing the amounts of yellow mustard used in treated samples and increasing the viscosity value. With the increase of yellow mustard paste in concentrations of $1 \%$ and $1.5 \%$ respectively the viscosity value raised from of $4150 \mathrm{cP}$ and $4251 \mathrm{cP}$.

Accordingly, viscosity value of treated sample with $1.5 \%$ concentrations of yellow mustard paste (M4) was observed as the highest viscosity and increased $11.5 \%$ comparing to the control sample.

According to the obtained results, the whole yellow mustard, having more than $5 \%$ Mucilage and especially neutral polysaccharides such as 1,4 - linked $\beta$-D-glucan and acidic pectic-like polysaccharide containing 1, 2 and 1,6-linked $\beta$-galactose, increases viscosity of the continuous phase and decreases the rate of separating oil particles in emulsion of mayonnaise. Finally, by increasing the consumptive mustard, viscosity of product increases. The results of this study confirms the studies carried out by Liu and his colleagues in 2005, about the effects of yellow mustard Mucilage on the rheological properties of buckwheat and pea starches [20].

\section{Color values of mayonnaise samples}

Table 7 shows the effect of different concentrations of yellow

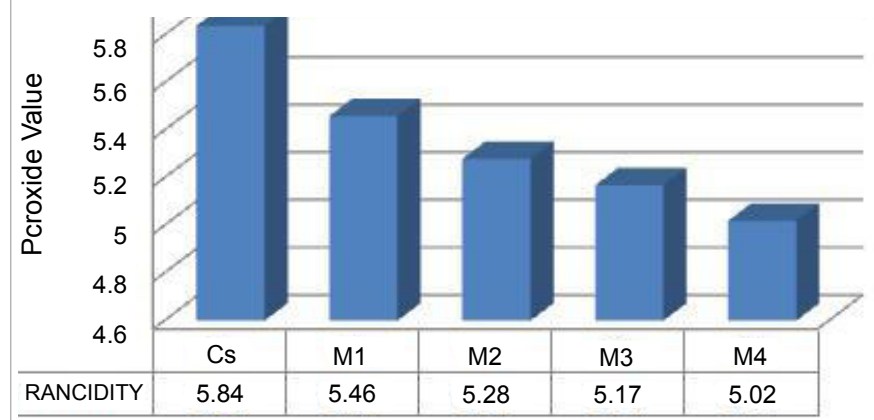

Figure 1: Peroxide value in treated samples by mustard paste and control sample (CS) at the intervals of 3 month after production.

\begin{tabular}{|l|l|l|l|}
\hline sample name & *Viscosity & T.P\% & Temperature (c) \\
\hline F11 & $3759 \pm 4.17$ & 66.4 & 21.8 \\
\hline F12 & $3802 \pm 3.75$ & 65.1 & 21.6 \\
\hline F13 & $3837 \pm 2.90$ & 59.9 & 21.4 \\
\hline F14 & $3875 \pm 3.00$ & 58.2 & 23.2 \\
\hline F15 & $3898 \pm 1.45$ & 57.3 & 23.8 \\
\hline M1 & $3928 \pm 1.45$ & 61.5 & 22.2 \\
\hline M2 & $4018 \pm 3.17$ & 66.2 & 21.6 \\
\hline M3 & $4150 \pm 3.28$ & 71.8 & 21.9 \\
\hline M4 & $4251 \pm 1.45$ & 73.7 & 22.4 \\
\hline CS & $3707 \pm 3.71$ & 62.6 & 21.7 \\
\hline
\end{tabular}

aMean value of tree measurements, Statistically significant $(p \leq 0.05)^{*}$.

Table 6: Viscosity value (cP) of treated samples and control sample (CS).

\begin{tabular}{|l|l|l|l|l|}
\hline \multirow{2}{*}{ Sample Name } & & \multicolumn{3}{|c|}{ Color values } \\
\cline { 2 - 5 } & $\Delta \mathrm{E}^{*}$ & a-value * & b-value * & I-value * \\
\hline F11 & 0.02 & $-0.64 \pm 0.01$ & $12.53 \pm 0.01$ & $91.83 \pm 0.01$ \\
\hline F12 & 1.06 & $-0.44 \pm 0.03$ & $12.88 \pm 0.01$ & $91.46 \pm 0.02$ \\
\hline F13 & 1.15 & $-0.69 \pm 0.02$ & $13.08 \pm 0.01$ & $91.22 \pm 0.01$ \\
\hline F14 & 2.47 & $-0.72 \pm 0.02$ & $13.42 \pm 0.01$ & $89.82 \pm 0.02$ \\
\hline F15 & 2.97 & $-0.58 \pm 0.00$ & $13.54 \pm 0.01$ & $89.30 \pm 0.01$ \\
\hline M1 & 0.79 & $-0.94 \pm 0.01$ & $12.73 \pm 0.01$ & $91.74 \pm 0.01$ \\
\hline M2 & 1.05 & $-0.83 \pm 0.03$ & $12.91 \pm 0.02$ & $91.27 \pm 0.01$ \\
\hline M3 & 1.70 & $-0.97 \pm 0.01$ & $13.47 \pm 0.02$ & $91.04 \pm 0.01$ \\
\hline M4 & 1.79 & $-1.13 \pm 0.03$ & $13.58 \pm 0.02$ & $90.98 \pm 0.02$ \\
\hline CS & 0.00 & $-0.39 \pm 0.03$ & $12.26 \pm 0.01$ & $91.97 \pm 0.01$ \\
\hline
\end{tabular}

${ }^{\mathrm{a}}$ Mean value of tree measurements.

Table 7: L-value, a-value and b-value in produced treatments ${ }^{\mathrm{a}}$.



Figure 2: L-Value in treated samples and control sample.

mustard powder $(0.0 \%, 0.1 \%, 0.2 \%, 0.3 \%, 0.4 \%$, and $0.5 \%)$ in samples $\left(\mathrm{F}_{11}-\mathrm{F}_{15}\right)$, mustard paste $(0.0 \%, 0.75 \%, 0.1 \%, 1.25 \%$ and $1.5 \%)$ in samples $\left(\mathrm{M}_{1}-\mathrm{M}_{4}\right)$ and control sample(CS) without mustard on the color values ( $\left.L^{\star} a^{\star} b^{\star}\right)$ of mayonnaise samples.

Statistical analysis of the means of Hunter Spectrophotometer using GLM ANOVA by SAS software showed a statistically significant difference in indexes L, b, a in mayonnaise samples at the $95 \%$ level of significance. Statistical analysis of ANOVA comparing all treatments with control group showed a Statistically significant difference between produced treatments $(\Delta E)$ and control sample $(\mathrm{p} \leq 0.05)$.

$$
\begin{aligned}
& \Delta L=L_{S M P}-L_{S T D} \Delta b=b_{S M P}-b_{S T D} \\
& \Delta a=a_{S M P}-a_{S T D} \Delta E=\sqrt{\Delta L^{2}+\Delta a^{2}+\Delta b^{2}}
\end{aligned}
$$

Based on the results of figure 2 , the sample containing $0.1 \%$ mustard powder $\left(\mathrm{F}_{11}\right)$ had the least color difference with the control sample (CS), and by increasing the yellow mustard powder in mayonnaise formulation from $0.1 \%$ to $0.5 \%$ the total color difference in the treated samples also increased to $2.95 \%$. The control sample (CS) had the highest a-value $(-0.39)$ and by increasing yellow mustard powder in mayonnaise formulation from $0.1 \%$ to $0.5 \%$, a-value decreased to -1.13 . The negative digits in a-value show the tendency of the product to green color, so by increasing the concentrations of mustard powder in all the mayonnaise samples, concerning a-value, there was a slight tendency towards green color. Based on the results, control sample (CS) had the least amount of b-value and by increasing the amount of mustard powder from $0.1 \%$ to $1.5 \%$, b-value also increased to 13.5 . And in spite of increasing the concentrations of yellow mustard paste in the formulation of mayonnaise in samples $M_{1}$ and $M_{2}$, b-value decreased 


\begin{tabular}{|c|c|c|c|c|c|c|}
\hline Sample name & Colour ${ }^{*}$ & Consistency* & Odour* & texture & Flavor* & Overall* acceptability \\
\hline F11 & $4.80 \pm 1.06$ & $4.63 \pm 1.02$ & $4.73 \pm 0.98$ & $4.93 \pm 1.01$ & $4.33 \pm 1.22$ & $4.70 \pm 1.20$ \\
\hline F12 & $4.50 \pm 1.13$ & $4.70 \pm 1.03$ & $4.10 \pm 0.92$ & $5.10 \pm 1.02$ & $4.63 \pm 1.12$ & $4.93 \pm 0.98$ \\
\hline F13 & $4.46 \pm 1.16$ & $4.73 \pm 1.01$ & $4.13 \pm 0.89$ & $5.00 \pm 1.08$ & $4.80 \pm 1.06$ & $4.40 \pm 0.93$ \\
\hline F14 & $4.33 \pm 0.88$ & $4.83 \pm 0.98$ & $4.30 \pm 0.98$ & $4.93 \pm 1.04$ & $4.20 \pm 1.06$ & $4.33 \pm 0.88$ \\
\hline F15 & $4.20 \pm 0.96$ & $5.00 \pm 0.90$ & $4.53 \pm 1.10$ & $5.23 \pm 1.04$ & $4.13 \pm 1.00$ & $4.13 \pm 1.07$ \\
\hline M1 & $4.93 \pm 1.04$ & $5.20 \pm 0.96$ & $5.13 \pm 0.89$ & $5.20 \pm 1.03$ & $4.60 \pm 1.19$ & $5.03 \pm 0.46$ \\
\hline M2 & $4.80 \pm 0.96$ & $5.23 \pm 0.81$ & $4.83 \pm 1.01$ & $5.10 \pm 1.06$ & $4.93 \pm 0.98$ & $5.33 \pm 0.80$ \\
\hline M3 & $4.63 \pm 1.03$ & $5.40 \pm 0.77$ & $4.70 \pm 1.02$ & $5.13 \pm 1.17$ & $4.60 \pm 1.27$ & $4.80 \pm 1.06$ \\
\hline M4 & $4.40 \pm 0.96$ & $540 \pm 1.06$ & $5.10 \pm 0.95$ & $5.10 \pm 1.06$ & $4.43 \pm 0.88$ & $4.40 \pm 0.96$ \\
\hline CS & $5.40 \pm 0.96$ & $4.50 \pm 1.10$ & $4.30 \pm 0.93$ & $5.03 \pm 0.99$ & $3.93 \pm 1.15$ & $4.10 \pm 0.88$ \\
\hline
\end{tabular}

${ }^{a}$ Means value of 30 measurements. Statistically significant $(p \leq 0.05)^{*}$.

Table 8: Score Means of the sensory evaluation in treated samples ${ }^{\mathrm{a}}$.

respectively to 12.73 and 12.91 , and with the increase of mustard paste in $\mathrm{M}_{4}$, b-value increased to 13.6. The positive digits in b-value show the tendency of the product towards yellow color, so with the increase of mustard powder in the formulation of mayonnaise, $b$-value had a tendency towards yellow color. Therefore by increasing the mustard powder and the increase of anthocyanin contents, existing in the yellow mustard, the amount of $\Delta E$ increased in the treated samples. With an increase in the concentrations of yellow mustard paste in the formulation of mayonnaise in $\mathrm{M}_{1}$ and $\mathrm{M}_{2}$, L-value increased respectively to 91.74 and 91.71 , and the color of the mayonnaise got lighter. Therefore the darkness problem of mayonnaise was solved to a great extent by increasing the concentrations of yellow mustard in the formulation of mayonnaise. At last the amount of L-value in the samples containing $1.25 \%$ and $1.5 \%$ decreased respectively to 91.04 and 91.98. The results of this part of the research showed a confirmation to the works of Reyes and Zavalus [21], Takada et al. [22] and so on $[9,22,23]$.

\section{Sensory evaluation of treated samples}

Table 8 shows the effects of different concentrations of yellow mustard powder $(0.0 \%, 0.1 \%, 0.2 \%, 0.3 \%, 0.4 \%$, and $0.5 \%)$ in samples $\left(\mathrm{F}_{11}-\mathrm{F}_{15}\right)$ and mustard paste $(0.0 \%, 0.75 \%, 0.1 \%, 1.25 \%$ and $1.5 \%)$ in samples $\left(\mathrm{M}_{1}-\mathrm{M}_{4}\right)$ and control sample (CS) on color hue, taste, odour, stability and overall acceptability of mayonnaise samples.

ANOVA GLM at the 95\% level of significance showed a meaningful difference of the data from stability, color, flavor and different general acceptances, and a lack of statistically significant difference in the data from textual in treated samples. Analysis of the results of Duncan test, in most cases showed a statistically significant difference among the data of the different aforementioned tests and with that of control group except the data from the analysis of texture properties. So according to the table 8 , the aforementioned sensory evaluating group did not distinguish between the scoring of the textual properties of treated samples. Regarding the flavor, the control sample (CS) scored the least (3.93), and with the increase of mustard content from $0 \%$ to $0.3 \%$ flavor score increased to 4.80 , and improved to a great extent which shows the yellow mustard property as a main component of mayonnaise for flavoring. So based on the results of flavor scoring, with the increase of the content of mustard powder to $0.4 \%$ and $0.5 \%$, flavor score of mayonnaise decreased. It is because of an increase in the content of Isothiocyanate existing in the mayonnaise due to the activities of enzyme myrosinase in the yellow mustard powder and finally causing pungent flavor in the mayonnaise in higher concentrations of mustard powder. It should be mentioned that enzyme myrosinase in mustard powder is active due to not applying heating treatment. With the increase of mustard paste in $1 \%$, the mean of flavor score increased to 4.76 . It is because of the use of heating treatment in mustard paste, deactivation of enzyme myrosinase and the decrease in the content of the Isothiocyanate and therefore the decrease of pungent flavor in mustard paste. So, the use of heating treatment and the production of mustard paste made the use of high concentrations of mustard paste (0.75\%-1.5\%) possible [24]. The results showed a confirmation of the findings of Balint et al. [25]. The sensory evaluating group gave higher scores to the smell samples of mayonnaise containing mustard paste $(0.75 \%-1.5 \%)$ in comparison with the samples containing mustard powder (0.1\%-o.5\%) and control sample [4, 25].

\section{Conclusion}

Regarding the results obtained from the effects of yellow powder mustard, at the second step of research, using heating treatment the myrosinase enzyme was inactivated in the solution of hot vinegar. So that considering the reduction of the isothiocyanate compounds resulting from myrosinase activity, the pungent taste of yellow mustard powder was greatly reduced. The Results obtained from measuring viscosity, stability and peroxide values concluded that treated samples by using mustard paste and in high concentrations of $(0.75-1.50) \%$, and without chemical preservatives compared with samples of powder mustard and in concentrations of (0.1-0.5)\% indicated an increase in viscosity to the rate $11.5 \%$, improvement of emulsion stability to the rate of $76.70 \%$, decreasing the peroxide and rancidity to the value of $14 \%$ in mayonnaise sample $\mathrm{M}_{4}$ (containing $1.5 \%$ yellow mustard paste) compared to the control. At last, remarkably improving in flavor (taste), color, stability and overall acceptability, values of $1 \%$ yellow mustard as paste mustard to increase viscosity, improve the suspension stability and reduction of peroxide value and Mayonnaise rancidity, was identified as the most appropriate sample according to acceptable results of sensory evaluation.

\section{Acknowledgements}

Hereby we would like to appreciate the cooperation's of Institute of Food and Agriculture, Standard and Industrial Research Organization and Mahram Food Industrial Company in providing finance and laboratory facilities.

\section{References}

1. Fahey JW, Zalcmann AT, Talalay P (2001) The chemical diversity and distribution of glucosinolates and isothiocyanates among plants. Phytochemistry 56: 5-51.

2. Aluko RE, McIntosh T, Mupondwa FK (2005) Comparative study of the polypeptide profiles and functional properties of Sinapis alba and Brassica juncea seed meals and protein concentrates. J Sci Food Agr 85: 1931-1937.

3. Weber FE, Taillie SA, Stauffer KR (1974) Functional Characteristics of Mustard Mucilage. J Food Sci 39: 461-466. 
Citation: Milani MA, Mizani M, Ghavami M, Eshratabadi P (2013) The Physico-Chemical Influences of Yellow Mustard Paste - Comparison with the Powder in Mayonnaise. J Food Process Technol 4: 210. doi:10.4172/2157-7110.1000210

4. Neudecker T, Henschler D (1985) Allyl isothiocyanate is mutagenic in Salmonella typhimurium. Mutat Res 156: 33-37.

5. Cserhalmi Zs, Markus Zs, Czukor B, Barath A, Toth M (2000) Physico-chemical properties and food utilization possibilities of RF-treated Mustard seed. Innovative Food Science \& Emerging Technologies 1: 251-254.

6. Liu H, Eskin MNA, Cui SW (2003) Interaction of wheat and rice starches with yellow mustard mucilage. Food Hydrocolloid 17: 863-869.

7. Bennett R, Kiddle G, Wallsgrove RM (1997) Involvement of Cytochrome P450 in Glucosinolate Biosynthesis in White Mustard. Plant Physiol 114: 1283-1291.

8. Buskov S, Hasselstrøm J, Olsen CE, Sørensen H, Sørensen JC, et al. (2000) Supercritical fluid chromatography as a mothod of analysis for the determination of 4-hydroxbenzylglucosinolate degradation products. J Biochem Biophys Methods 43: 157-174.

9. Kırca A, Ozkan M, Cemeroglu B (2007) Effects of temperature, solid content and $\mathrm{pH}$ on the stability of black carrot anthocyanins. Food Chem 101: 212-218.

10. Shahidi F, Wanasundara UN, Amarowicz R (1994) Natural antioxidants from low-pungency mustard flour. Food Res Int 27: 489-493.

11. Honda T, Tatsuzawa F, Kobayashi N, Kasai H, Shigihara A, et al. (2005) Acylated anthocyanins from the violet-blue flowers of Orychophragonus violaceus. Phytochemistry 66: 1844-1851.

12. Liu H, Eskin NAM (1998) Interactions of native and acetylated pea starch with yellow mustard mucilage, locust bean gum and gelatin. Food Hydrocolloid 12 $37-41$

13. MC Carthy TL, Kerry JP, Kerry JF, Lynch PB, Buckley DJ (2001) Evaluation of the antioxidant potential of natural food/plant extracts as compared with synthetic antioxidants and vitamin $\mathrm{E}$ in raw and cooked pork patties. Meat sci 58: 45-52.
14. Kelly PJ, Bones A, Rossiter JT (1998) Sub-cellular immunolocalization of the glucosinolate sinigrin in seedlings of Brassica juncea. Planta 206: 370-377.

15. Peterson J (1992) Mayonnaise Based sauces. Sauces, classical and contemporary sauce making.

16. Astrom A, Langton M, Marie A (1998) Microstructure in relation to the textual properties of mayonnaise. The Swedish institute for food and biotechnology. Got ebon Sweden

17. Codex Stan (2005) Codex General Standard for Food Additives.

18. American Oil chemists Society (1990) AOAC official methods of analysis, peroxide value of oils and fats, titration method.

19. U.S. Enviromental protection Agency (1995) Emissinfactor documentation for pickles, sauces, and salad dressings.

20. Balke DT, Diosady LL (2005) Rapid aqueous extraction of mucilage from whole white mustard seed. Food Res Int. 33: 347-356.

21. Reyes LF, Zavallos LC (2007) Degradation kinetics and colour of anthocyanins in aqueous extracts of purple- and red-flesh potatoes (Solanum tuberosum L.). Food Chem 100: 885-894.

22. Takeda K, Fischer D, Grisebach H (1988) Anthocyanin composition of Sinapis alba, light induction of enzymes and biosynthesis. Phytochemistry 27: 1351 1353.

23. Hemingway JS (1995) The Mustard Species: Condiment and Food Ingredient Use and Potential as Oilseed Crops. In Kimber D and McGregor DI (Eds) Brassica Oilseeds, Production and Utilisation. CAB International, Wallingford, UK. 373-383.

24. VanEylen D, Hendrickx M, Van Loey A (2006) Temperature and pressure stability of mustard seed (Sinapis alba L.) myrosinase. Food Chem 97: 263271.

25. Ildiko SG, Klara KA, Marianna TM, Barath A, Zsuzsanna MB, et al. (2006) The effect of radio frequency heat treatment on nutritional and colloid-chemical properties of different white mustard (Sinapis alba L.) varieties. Innovative Food Science \& Emerging Technologies 7: 74-79. 